\title{
Book Review: Cannabinoids and Neuropsychiatric Disorders
}

\author{
Anthony L. Murkar ${ }^{1 *}$ and Rébecca Robillard ${ }^{1,2}$ \\ ${ }^{1}$ Sleep Research Unit, The Royal's Institute of Mental Health Research, Ottawa, ON, Canada, ${ }^{2}$ University of Ottawa School \\ of Psychology, Ottawa, ON, Canada
}

Keywords: cannabis (marijuana), psychiatry, psychopathology, psychopharmacology, cannabinoids (THC)

\author{
A Book Review on \\ Cannabinoids and Neuropsychiatric Disorders
}

Eric Murillo-Rodriguez, S. R. Pandi-Perumal, and Jaime M. Monti (Cham: Springer International Publishing), 2021, XVII, 153 pages, ISBN: 978-3-030-57369-0

\section{INTRODUCTION}

Despite being quite well-studied, cannabis may be one of the most poorly understood compounds in molecular neuropsychiatry and pharmacology. This is partially due to the diverse behavioral effects of its constituent compounds themselves, the non-selective nature of the exogenous cannabinoids, and the legal hurdles affecting research outputs. The widespread use of marijuana for medical purposes (a complex mixture of over 400 chemical constituents found in widely varying quantities) rather than pure, isolated compounds also complicates the dissection of potential therapeutic applications. The book "cannabinoids and neuropsychiatric disorders" (Murillo-Rodriguez et al., 2021) provides an in-depth exploration of cannabis, its constituent molecules, and synthetic variants-as well as their effects on various psychiatric conditions. It provides the reader with a comprehensive introduction to the complex composition of $C$. sativa L. and our current understanding of the pharmacological actions of its constituent compounds (as well as the endogenous cannabinoids and synthetic products). It is a useful read for anyone with an interest in the psychopharmacology of medical cannabis, researchers, and healthcare practitioners alike.

\section{SUMMARY}

Specialty section: This article was submitted to

Psychopathology, a section of the journal

Frontiers in Psychology

Received: 19 April 2021 Accepted: 03 May 2021

Published: 28 May 2021

Citation:

Murkar AL and Robillard R (2021)

Book Review: Cannabinoids and

Neuropsychiatric Disorders.

Front. Psychol. 12:697434.

doi: 10.3389/fpsyg.2021.697434

In the foreword to the book provided by R. Mechoulam, a critical problem of modern medicine's current stance on cannabinoids is highlighted: "medical cannabis," a complex mixture of many compounds (often in unknown quantities, and many of whose actions we do not fully understand), is reaching the public as a poorly understood yet widely available medicinal product. In order for medical cannabis to be appropriately incorporated into clinical practice, it is therefore key for healthcare practitioners to have sufficient grasp of what they are prescribing and how it can affect the various conditions encountered in their practice. This book provides a timely synthesis, with an in-depth characterization of the different classes of cannabinoids and their activities.

Overall, the book consists of nine chapters providing the reader with a global overview of the current state of our pharmacological understanding of cannabinoids and the relevance of these compounds to various psychiatric conditions for which cannabis has been prescribed or studied. Chapter 1 is dedicated to the different varieties of cannabinoids while also covering many of the other non-cannabinoid compounds identified in the cannabis plant (e.g., the terpenoids) that could 
also possess their own therapeutic qualities. Chapters 2 and 3 then discuss the mechanisms believed to be responsible for the actions of cannabinoids. The first three chapters together provide an excellent overview of the cannabinoids and their activities. They also touch on the important and relatively recent discovery that many cannabinoids (both synthetic agonists and antagonists, as well as phytocannabinoids) can also act at novel orphan/recently deorphanized receptors (Begg et al., 2005; Ryberg et al., 2007; Huang et al., 2011; Brown et al., 2017) whose central distributions and functions we do not yet fully understand. Chapter 4 then discusses the clinical and pre-clinical evidence about the efficacy of cannabinoids garnered from clinical experimental models of both neuropsychiatric and non-neuropsychiatric conditions (with a particular emphasis on cancer, metabolic disorders/obesity, epilepsy, and neurodegenerative diseases).

The remaining chapters of the book then focus on the relevance of cannabinoids as interventions for various neuropsychiatric conditions. Chapters 5 through 8 contain an indepth review of disorders for which cannabis has been the most well-studied-including depression [as well as its association with cannabis use disorder (CUD); Ch. 5], Alzheimer's disease (Ch. 6), Huntington's disease (Ch. 6), Parkinson's disease (Ch. 6), epilepsy (Ch. 7), and multiple sclerosis (Ch. 8). Finally, Chapter 9 concludes with a more general review of several additional disorders including anxiety disorders, schizophrenia, autismspectrum disorders, attention-deficit hyperactivity disorder, and addiction (both in terms of CUD itself and of endocannabinoidmediated modulation of the reward networks by other addictive substances). It also places a particular emphasis on what is known about modulation of the cannabinoid receptors in each condition.

\section{EVALUATION}

Overall, the book is clear, well-written, and provides an in-depth examination of the pharmacology of the cannabinoids that could be highly relevant for clinicians aiming to better understand products that their patients may be taking (either by prescription or outside of the guidance of healthcare practitioners) and the

\section{REFERENCES}

Begg, M., Pacher, P., Bátkai, S., Osei-Hyiaman, D., Offertáler, L., Mo, F. M., et al. (2005). Evidence for novel cannabinoid receptors. Pharmacol. Ther. 106, 133-145. doi: 10.1016/j.pharmthera.2004.11.005

Brown, K. J., Laun, A. S., and Song, Z.-H. (2017). Cannabidiol, a novel inverse agonist for GPR12. Biochem. Biophys. Res. Commun. 493, 451-454. doi: 10.1016/j.bbrc.2017.09.001

Bryan, J. L., Hogan, J., Lindsay, J. A., and Ecker, A. H. (2021). Cannabis use disorder and post-traumatic stress disorder: the prevalence of comorbidity in veterans of recent conflicts. J. Subst. Abuse Treat. 122:108254. doi: 10.1016/j.jsat.2020.108254

Huang, L., Ramirez, J. C., Frampton, G. A., Golden, L. E., Quinn, M. A., Pae, H. Y., et al. (2011). Anandamide exerts its antiproliferative actions on cholangiocarcinoma by activation of the GPR55 receptor. Lab. Invest. 91, 1007-1017. doi: 10.1038/labinvest.2011.62 effects these products may have on neuropsychiatric conditions. It is also highly relevant for researchers wishing to develop a better understanding of the chemical characterization of these compounds and their effects on behavior.

We do find one important limitation with the book, however. Although it provides in-depth coverage of several psychiatric conditions, a chapter on post-traumatic stress disorder (PTSD) and/or other Trauma- and Stressor-Related Disorders is notably absent. This is despite that cannabinoids have been used quite extensively in the treatment of PTSD (Jetly et al., 2015; Steenkamp et al., 2017; Veterans Affairs Canada, 2019). Among conditions treated by cannabis, PTSD is perhaps the one with the strongest theoretical basis to support its indication for the condition (Lisboa et al., 2010; Neumeister, 2013; Neumeister et al., 2013; Pietrzak et al., 2014). High rates of co-occurring CUD with PTSD have also indicated this as a key area of concern with regards to mental health comorbidities (Bryan et al., 2021). Thus, it is one of the primary conditions associated with cannabis use that clinicians will likely seek to better understand.

\section{DISCUSSION}

Overall, the editors and authors of this book have presented an excellent resource for readers interested in the endocannabinoid system and its role in neuropsychiatry. Its coverage of the complex cannabinoid pharmacology, the actions of the cannabinoid receptors, and its thorough review of the constituents of the cannabis plant and their effects on various psychiatric conditions make it a helpful reference. Given the current landscape of cannabis use and emerging potential therapeutic applications, ascertaining a greater understanding of the intricacies of the cannabinoids is an area of great importance, both for research and clinical practice-and this book offers a great summary of the current state of the literature.

\section{AUTHOR CONTRIBUTIONS}

All authors listed made substantial contributions to the conception, formulation, writing, editing of this review, and read and approved the final manuscript.

Jetly, R., Heber, A., Fraser, G., and Boisvert, D. (2015). The efficacy of nabilone, a synthetic cannabinoid, in the treatment of PTSD-associated nightmares: a preliminary randomized, double-blind, placebo-controlled cross-over design study. Psychoneuroendocrinology 51, 585-588. doi: 10.1016/j.psyneuen.2014.11.002

Lisboa, S. F., Reis, D. G., da Silva, A. L., Corrêa, F. M., Guimaraes, F. S., and Resstel, L. B. (2010). Cannabinoid CB1 receptors in the medial prefrontal cortex modulate the expression of contextual fear conditioning. Int. J. Neuropsychopharmacol. 13, 1163-1173. doi: 10.1017/S146114571000 0684

Murillo-Rodriguez, E., Pandi-Perumal, S. R., and Monti, J. M. (2021). Cannabinoids and Neuropsychiatric Disorders. Cham: Springer. doi: 10.1007/978-3-030-57369-0

Neumeister, A. (2013). The endocannabinoid system provides an avenue for evidence-based treatment development for PTSD. Depress. Anxiety 30, 93-96. doi: $10.1002 /$ da. 22031 
Neumeister, A., Normandin, M. D., Pietrzak, R. H., Piomelli, D., Zheng, M.-Q., Gujarro-Anton, A., et al. (2013). Elevated brain cannabinoid CB1 receptor availability in post-traumatic stress disorder: a positron emission tomography study. Mol. Psychiatry 18, 1034-1040. doi: 10.1038/mp.2013.61

Pietrzak, R. H., Huang, Y., Corsi-Travali, S., Zheng, M.-Q., Lin, S., Henry, S., et al. (2014). Cannabinoid type 1 receptor availability in the amygdala mediates threat processing in trauma survivors. Neuropsychopharmacology 39:2519. doi: $10.1038 /$ npp.2014.110

Ryberg, E., Larsson, N., Sjögren, S., Hjorth, S., Hermansson, N.-O., Leonova, J., et al. (2007). The orphan receptor GPR55 is a novel cannabinoid receptor. $B r$. J. Pharmacol. 152, 1092-1101. doi: 10.1038/sj.bjp.0707460

Steenkamp, M. M., Blessing, E. M., Galatzer-Levy, I. R., Hollahan, L. C., and Anderson, W. T. (2017). Marijuana and other cannabinoids as a treatment for posttraumatic stress disorder: a literature review. Depress. Anxiety 34, 207-216. doi: $10.1002 /$ da. 22596
Veterans Affairs Canada (2019). Review of Marijuana for Medical Purposes Veterans Affairs Canada. Available online at: https://www.veterans.gc.ca/eng/ about-vac/publications-reports/reports/departmental-audit-evaluation/2016review-marijuana-medical-purposes (accessed November 17, 2020).

Conflict of Interest: The authors declare that the research was conducted in the absence of any commercial or financial relationships that could be construed as a potential conflict of interest.

Copyright $\odot 2021$ Murkar and Robillard. This is an open-access article distributed under the terms of the Creative Commons Attribution License (CC BY). The use, distribution or reproduction in other forums is permitted, provided the original author(s) and the copyright owner(s) are credited and that the original publication in this journal is cited, in accordance with accepted academic practice. No use, distribution or reproduction is permitted which does not comply with these terms. 